\title{
François-René De Chateaubriand, I Natchez
}

\section{Fabio Vasarri}

\section{(2) OpenEdition}

\section{Journals}

\section{Edizione digitale}

URL: http://journals.openedition.org/studifrancesi/27711

DOI: 10.4000/studifrancesi.27711

ISSN: 2427-5856

\section{Editore}

Rosenberg \& Sellier

\section{Edizione cartacea}

Data di pubblicazione: 31 décembre 2006

Paginazione: 614

ISSN: 0039-2944

\section{Notizia bibliografica digitale}

Fabio Vasarri, «François-René De Chateaubriand, I Natchez », Studi Francesi [Online], 150 (L | |II) | 2006 online dal 30 novembre 2015, consultato il 08 novembre 2020. URL : http://journals.openedition.org/ studifrancesi/27711 ; DOI : https://doi.org/10.4000/studifrancesi.27711

\section{Questo documento è stato generato automaticamente il 8 novembre 2020.}

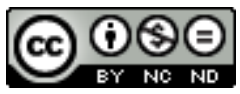

Studi Francesi è distribuita con Licenza Creative Commons Attribuzione - Non commerciale - Non opere derivate 4.0 Internazionale. 


\title{
François-René De Chateaubriand, I Natchez
}

\author{
Fabio Vasarri
}

\section{NOTIZIA}

FRANÇOIS-RENÉ DE CHATEAUBRIAND, I Natchez, a cura di Ivanna ROSI e Filippo MARTELLUCCI, Firenze, Le Lettere, 2004, pp. 486, ill.

1 Il volume va salutato come un evento importante per gli studi su Chateaubriand. Si tratta della prima traduzione italiana integrale di questa saga amerindiana, opera giovanile spesso menzionata ma misconosciuta e autentico serbatoio di tematiche sviluppate nella produzione posteriore più nota. Basti ricordare che i più fortunati Atala e René sono in origine episodi dei Natchez. Basato su un episodio reale del colonialismo francese in Louisiana, il massacro della tribù dei Natchez nel 1729, il progetto narrativo di Chateaubriand conosce una vicenda travagliata. Ideato all'indomani della presa della Bastiglia e redatto in gran parte tra il 1794 e il 1799, durante l'emigrazione inglese, il testo è pubblicato solo nel 1826, in occasione della raccolta Ladvocat delle opere dell'autore. Nel frattempo, tuttavia, Les Natchez hanno subito trasformazioni radicali, tra cui uno slittamento di genere, dalla narrativa esotica e gotica all'epopea in prosa. Fin dal 1798, l'autore intraprende la riscrittura neoclassica del nucleo romanzesco originario ma si interrompe a metà, certo avvertendo la vanità e l'inattualità dell'impresa. Il testo pubblicato esibisce quindi vistosamente la sua «incompiutezza» e la sua indecisione: a una prima parte tardoepica e stilizzata segue una seconda parte romanzesca, più informe e magmatica, e più vicina all'assetto primitivo. Il fallimento del progetto trova una controparte positiva non solo nelle sezioni più riuscite del romanzo, ma nel suo valore emblematico rispetto all'evoluzione coeva della narrativa francese e nella sua insospettata modernità.

2 L'edizione curata dai due studiosi è estremamente affidabile. Con un ardito ma suggestivo restauro editoriale, il testo del romanzo-epopea è incorniciato dal prologo e 
dall'epilogo di Atala, pubblicati fin dal 1801 ma originariamente destinati ai Natchez. La traduzione a due mani, che sfrutta la bipartizione del testo, è fluida e si avvale di ampie conoscenze specifiche. Gli apparati formano un insieme esauriente, comprensivo di notizie sulle fonti, sulle coordinate storico-geografiche e sulla genesi del testo, dovute in particolare a Filippo Martellucci. La bellissima e mal nominata «introduzione» di Ivanna Rosi merita una segnalazione a parte. Articolato in varie sezioni, questo contributo («René e la fantasmagoria indiana», pp. V-XCV) costituisce un saggio monografico di notevole sensibilità e penetrazione. Nel corso della sua disamina, la studiosa mostra le molteplici stratificazioni letterarie, antropologiche e ideologiche dei Natchez; sul piano tematico, affronta con un approccio bachelardiano e durandiano il complesso immaginario di Chateaubriand, privilegiandone le multiformi figurazioni materne che si oppongono alla spinta pessimista e funebre del testo. Inoltre, affronta con successo i misteri di René, sottoponendo la novella omonima e il romanzo-poema amerindiano a un confronto serrato e approdando a una lettura nuova e stimolante del motivo incestuoso. Le contraddizioni del giovane saturnino si attenuano se ipotizziamo un'iniziale concezione positiva e «selvaggia» dell'amore adelfico, anteriore a tabù $\mathrm{e}$ censure. Esempio, tra non pochi altri, dell'apporto di una lettura critica che, pur rigorosa, si segnala per la sua libertà interpretativa e per un contatto ravvicinato con il testo. 